NISSUNA UMANA INVESTIGAZIONE SI PUO DIMANDARE VERA SCIENZIA S'ESSA NON PASSA PER LE MATEMATICHE DIMOSTRAZIONI LEONARDO DA VINCI

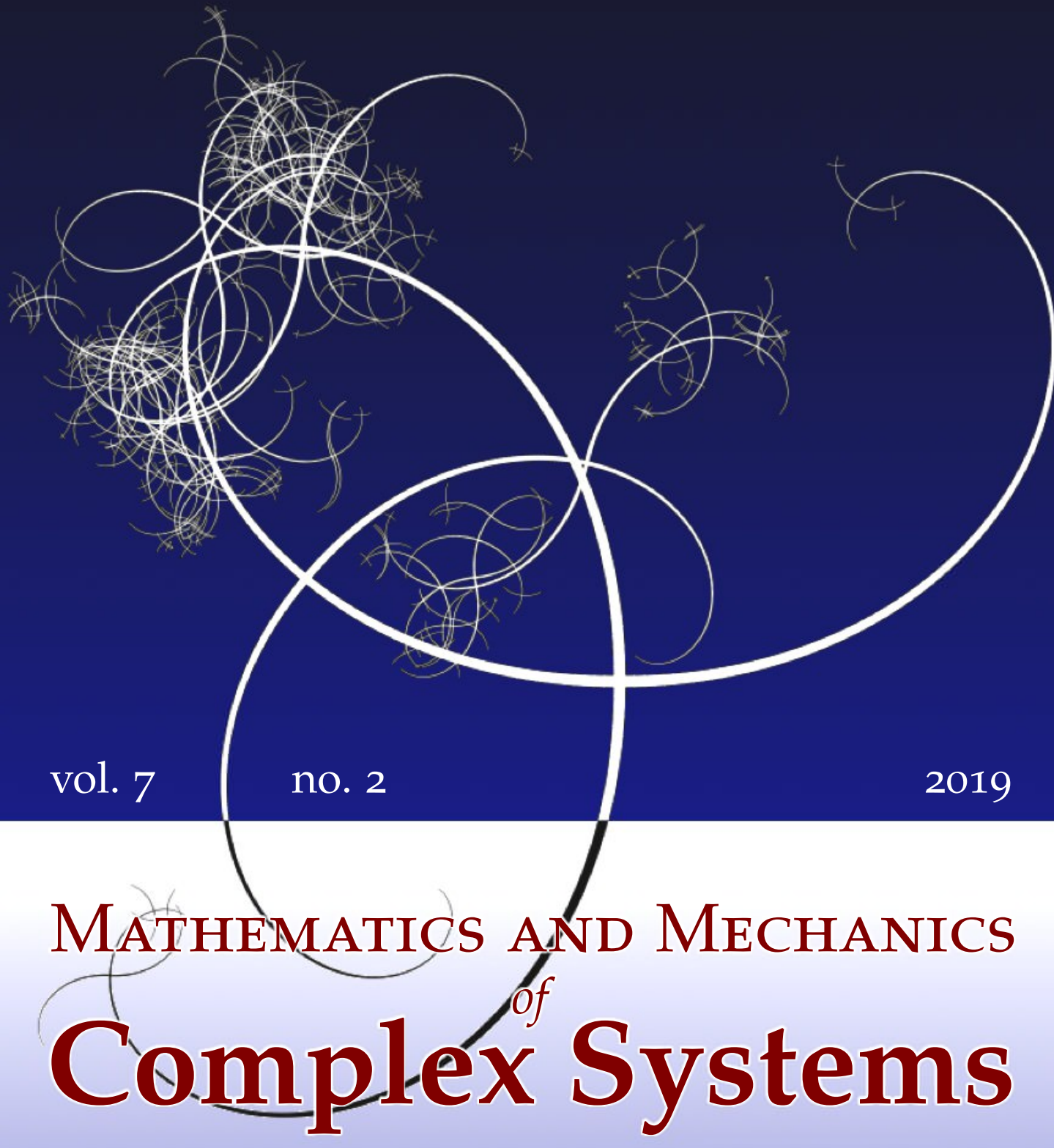

Ksenia P. Frolova, Polina M. Grigoreva, Konstantin E. LEZHneV AND GRIGORIY V. PADERIN

A MODEL OF THE PROPPANT FLOWBACK SETUP OF THE THEORETICAL FRAMEWORK 


\title{
A MODEL OF THE PROPPANT FLOWBACK SETUP OF THE THEORETICAL FRAMEWORK
}

\author{
KSENIA P. FROLOVA, \\ Polina M. Grigoreva, Konstantin E. LezhneV \\ AND GRIGORIY V. PADERIN
}

\begin{abstract}
Proppant flowback control is one of the main issues in hydraulic fracture modeling since the propping agent maintains the crack in an open state and therefore provides oil inflow to the wellbore. The main objective of this paper is to determine the conditions that can lead to proppant flowback during the direct operation of the well. The main outcome of this paper is an evolution criterion for proppant flowback occurrence, which takes the external pressures affecting the proppant particles, the proppant properties, and the crack opening width into account. We propose a two-component continuum model consisting of the proppant and the oil to find the stress-strain state of the proppant and thereby to obtain the stress components in the evolution criterion. We solve both a stationary problem for estimating the probability of the proppant flowback occurrence under regular conditions as well as a transient problem for taking the possibility of fast changing external conditions into account.
\end{abstract}

\section{Introduction}

Proppant flowback is a process of producing a propping agent from a hydraulically created cleavage fracture during extraction of the hydrocarbons or treatment of the wellbore. This process can significantly increase well operation costs due to decreases in the crack permeability when the proppant pack used for keeping it open is removed leading to its closure. Moreover, the entrained proppant moves with the fluid to the wellbore and increases the risk of mechanical damage of the wellbore equipment.

Proppant flowback and its mechanisms were extensively studied over the last 30 years due to the importance of its control. One of the first lab experiments used for studying the stability of a proppant pack is described in [Milton-Tayler et al. 1992]. It was shown that the fracture width, the closure stress, the pressure

\section{Communicated by Francesco dell'Isola.}

MSC2010: 70E50, 70E55, 74B15, 74F10, 76S05.

Keywords: proppant flowback, breakdown criterion, two-component continua, hydraulic fracture, pack stability, linear-elastic solid, rational mechanics approach. 
drawdown, and the proppant properties are key parameters affecting the proppant pack stability. Then a distinct-element model (DEM) of the proppant pack was conceived, which provided numerical results proving the laboratory data [Asgian et al. 1995]. Calculations performed for interacting cohesionless, unbonded proppant grains subjected to a drag force showed that the pack becomes unstable when a crucial ratio of mean grain diameter to the fracture width is reached. This numerical modeling also revealed the mechanism of proppant pack instability. At widths less than a critical value, a stable proppant arch is formed at the proppant pack face. This arch suffers deformations from compressive strains, resists extrusive stresses, and keeps the rest of the proppant grains inside the crack. If the drag forces are sufficiently high to make the arch fail, proppant production is started.

Some experiments on proppant flowback for proppants of different properties and a very simple mathematical model can also be found in [McLennan et al. 2015]. This model offers a phenomenological dependence of pressure in a proppant pack on oil production rate. In [Andrews and Kjørholt 1998] a phenomenological proppant pack stability criterion was suggested. It describes the proppant pack behavior in terms of a proppant free wedge concept, which states that in a three-dimensional space with axes of closure stresses, pressure drawdown, and fracture width there is a shell, the points inside of which are points of proppant pack stability. According to this concept, the maximum stable fracture function was chosen in a polynomial form when fitting the experiment results. However, this choice shows that this criterion is incorrect for the case of critical condition values. In later work (e.g., in [Canon et al. 2003]) the criterion was corrected, but as it was based on measurement results that cannot be determined perfectly, such phenomenological criteria could give only an approximate probability for the start of proppant flowback. A model taking the ability of proppant flowback to stop with the closure of the crack or a decrease of the drag force into account should be more complex and preferably include time dependence and cumulative effects.

Some complex models for proppant flowback were already developed in [Aidagulov et al. 2007]. They include plastic flow of the proppant after pack stability loss and changes in porosity. These are significant when calculating the crack permeability. Nevertheless, the criterion for the beginning of proppant flowback is still determined phenomenologically: it is based on a Mohr-Coulomb failure criterion, which does not describe the mechanism of proppant arch crushing, and therefore can give only approximate results.

In summary, we can say that the development of the criteria of the proppant flowback is still of interest in science and industry. The criteria developed in this paper and the corresponding model will not only predict the beginning of the proppant flowback but also determine "safe" regimes of hydrocarbon production and wellbore treatment. 


\section{Flowback criterion}

Presently there exists no widely known criterion for proppant pack stability loss that takes all the main factors into account that, according to experimental studies, primarily affect the flowback, namely the ratio of the width of the crack opening to the diameter of the proppant grains, as well as the type and coating of the proppant. The phenomenological dependencies that were proposed in the literature acknowledge only the influence of a few specific factors. Flowback criteria proposed in continuum models do not consider the effects of the discreteness of the proppant pack. Discrete models are not based on criteria that consider the stress state of the whole modeling area. In the proposed model an attempt is made to take the most important conditions affecting proppant flowback into account and to describe more accurately the process that occurs when proppant pack stability is lost.

The purpose of this paper is to determine conditions under which the proppant is produced during the direct treatment of the wellbore. Generally, the main reasons for the flowback are

- low stresses acting on the fracture walls, which cannot keep the proppant in the crack,

- a huge force of hydrodynamic resistance, acting on proppant particles, which leads to a loss of stability of the proppant pack, and

- accumulation of internal stresses and deformations during long-term operation of the well and its cyclic use.

In addition to the above-listed reasons of flowback following from the experimental results presented in literature [Vo et al. 2014; Lu et al. 2016], the form and coating of the proppant grains affecting the internal friction forces between individual proppant particles have a significant effect on the removal process, which in turn affects the stability of the proppant pack. Furthermore, from experimental data and from results when modeling the proppant removal process by the distinct element method, it follows that the packing becomes unstable, starting with a certain ratio of the average grain diameter to the width of the crack opening.

We consider the known mechanism of the stability loss when the proppant flowback starts after the failure of the arch formed by proppant particles [Asgian et al. 1995]. Within the framework of our model, the compressive stresses holding the proppant particles in the arch are the principal stresses in the proppant acting along the axis directed perpendicular to the axis of the crack. Drag forces lead to the main stresses in the proppant, which are directed along the axis of the crack. We assume that a Coulomb dry friction force acts between the proppant particles. The corresponding friction coefficient depends on the surface roughness of the proppant, 
its coating, and other cohesive properties. This takes one of the important factors influencing the proppant transport into account.

As mentioned above, the main reasons affecting the proppant transport are the closure stress, the flow rate of the fluid through the proppant pack, and the ratio of the proppant grain diameter to the crack opening width. The influence of the closing stress and the flow rate on the stability of proppant pack can be taken into account mechanically, whereas the effect of the mentioned ratio is described mostly empirically. The experiments show that a proppant pack with one or two proppant particles in the arch is stable even at the low closure stresses and high fluid rates. However, if the crack width is too big, namely starting from 6-10 proppant grains (depending on the type of proppant; see, e.g., [Andrews and Kjørholt 1998; Barree and Conway 2001]), the flowback occurs at most of the treatment regimes. That means that starting with some value the discreteness of the arch plays a role no more. Concluding all the mentioned reasons, we suggest the flowback criterion

$$
\mu_{p} T_{p z z}<T_{p x x} k\left[1-\exp \left(\frac{d-z_{0}}{z_{0}}\right)\right]
$$

where $\mu_{p}$ is the coefficient of dynamic viscosity of proppant, $T_{p z z}$ and $T_{p x x}$ are the components of the stress tensor of proppant acting in the directions of the crack opening and the crack length, respectively, $k$ is the correction factor, $d$ is the diameter of the proppant grain, and $z_{0}=z_{2}-z_{1}$ is the fracture width, where $z_{1}$ and $z_{2}$ are the coordinates of the crack edges. The exponential expression is motivated by a three-parameter Weibull distribution characterizing, for example, the statistical variation of bending strength in brittle materials, such as glass or ceramics. In this context, the parameter $z_{0}$ in the numerator and in the denominator would, in general, be different. The $z_{0}$ in the numerator would be a characteristic threshold stress under which no failure can occur, whereas the $z_{0}$ in the denominator is simply a suitable normalization stress (see [Manderscheid and Gyekenyesi 1987] for details, especially the discussion around (1)). Here, obviously, both have been taken as equal for simplicity.

If we want the criterion not to be fulfilled such that, consequently, no flowback occurs, it is necessary for the closure stress to be large enough to exceed the stress tending to push the proppant particle out of the arch with some factor increasing with increasing crack opening width. In order to make the flowback criterion meaningful, this parameter $k$ should be chosen such that, at a critical ratio of the diameter of the proppant particle to the width of the crack opening, the multiplier is approximately equal to 1 . The value of the parameter $k$ differs with the value of the critical ratio: for $z_{0} / d \approx 5.5$ [Andrews and Kjørholt 1998] $k$ is equal to 1.79 and for $z_{0} / d \approx 10$ [Barree and Conway 2001] $k$ is equal to 1.67 . 
In addition, it should be taken into account that (1) is a local criterion, which can be violated at several points inside of the proppant pack. Then flowback would still not happen. Thus, this criterion is a "lower estimate" for the critical values of the production conditions at which the proppant will not be taken out. For a more accurate assessment, one can introduce an integral criterion, which will take the number of violations of this criterion throughout the entire volume of the proppant pack into account.

It should also be noted that in this paper the proppant removal process itself is not modeled. This process can be described by using proppant transport models based on multiphase medium mechanics models, which are widely used when describing proppant placement processes in a crack.

\section{Physicomathematical model}

According to the proppant flowback criterion presented in the previous section, it is necessary to know the values of the stress tensor components $T_{p z z}$ and $T_{p x x}$ apart from the proppant properties and the fracture geometry in order to estimate as to whether proppant flowback occurs. In this spirit, we present a model, which allows one to obtain the stress-strain state of a propping agent under loading.

The proppant behavior under loading can be described within different approaches, namely discrete, continuum, and crossbred ones. In this paper, we follow the continuum approach. This is motivated primarily by the fact that discrete models mostly describe the proppant flowback mechanism, but do not allow one to estimate the propping agent properties before and after the start of the flowback. Moreover, calculations based on the continuum model will take much less time than those involved in a discrete model.

We model a single transverse crack initiated in a horizontal well filled with a tightly packed proppant and oil flowing through. As has been already mentioned in the section devoted to the flowback criterion, we do not model the proppant removal process. In this respect, we solve a quasistatic problem for the proppant. We consider the deformation of the propping agent affected by the oil flow and take the possibility of occurring vacancies into account.

For a more accurate prediction of the proppant behavior, both stationary and nonstationary laminar oil flows are considered. The stationary flow of oil through a packed proppant allows one to investigate the influence of various physical and mechanical proppant properties on its behavior. Considering a transient flow of oil allows one to take a changing borehole pressure, changes in the rate of the oil flow, a pause and subsequent resumption of the well treatment, etc., into account.

To find the stress-strain state of the proppant, we consider a two-component continuum consisting of proppant and oil. We assume that at each point of space both 
fluid and proppant are simultaneously present. Their partial densities determine the mass fractions of each of the components. Note that we allow the possibility of the vacancies' occurrence by considering the proppant density as a function of space coordinates and time. Some information on continuum mixture theory relevant to this paper can be found in [Brazgina et al. 2016].

The wellbore and the rock surrounding the fracture are not considered directly in the framework of the investigated model and are not included as additional components in the multicomponent media. Their presence is accounted through boundary conditions.

When modeling each component of the continuum, it becomes necessary to establish the corresponding constitutive relations. In this context, we use some simplifying hypotheses.

Generally, the proppant is considered as a granular material. However, since in the present case the proppant is the only reason for preventing cleavage closing under the pressure caused by the surrounding rock, it has a sufficiently high density. According to numerical simulations and experimental evidence, such granular media possess not only volumetric, but also shear stiffness and their behavior are the same as for an elastically deformable solid under pressure. Moreover, we assume that the proppant, repacked after hydraulic fracturing is finished, undergoes small deformations. Finally, we assume the material of the propping agent to be isotropic.

The second component of the model, usually oil, is considered as a weakly compressible Newtonian fluid in order to satisfy experimental observations. Different correlations are used for different types of oil in order to determine the effect of the applied pressure on the oil compressibility. Since in this paper we would like to outline and study the general problem of proppant flowback and to predict as to whether it occurs or not, we assume that the oil is an incompressible fluid.

3.1. Balance and constitutive equations. We introduce a Cartesian coordinate system $(x, y, z)$, where the $x$ axis coincides with the direction of the crack length, the $z$ axis with the direction of its opening width, and the $y$ axis with the direction of the crack aperture (see Figure 1).

The mass balance for both components, namely oil and proppant, is

$$
\frac{\delta_{i} \rho_{i}}{\delta t}+\rho_{i} \nabla \cdot \boldsymbol{v}_{i}=0,
$$

where subscript $i=f, p$ refers to the components of the fluid or of the proppant, respectively, $\rho$ is the density, $\boldsymbol{v}_{i}$ is the velocity, and $\nabla$ is the differential operator with respect to spatial coordinates. The substantial (material) derivative $\delta_{i} / \delta t$ of a field quantity $\phi$ is defined as

$$
\frac{\delta_{i} \phi(\boldsymbol{r}, t)}{\delta t}=\frac{\partial \phi(\boldsymbol{r}, t)}{\partial t}+\boldsymbol{v}_{i} \cdot \nabla \phi(\boldsymbol{r}, t)
$$




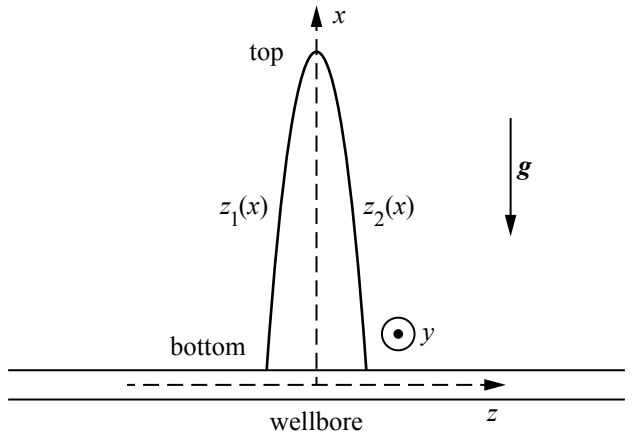

Figure 1. Schematic representation of the fracture.

where $\boldsymbol{r}$ is the position vector of the control volume (point of observation) or in other words of the certain area in space through which the structure moves as time passes (see, e.g., [Ivanova et al. 2016]).

Since the fluid is assumed as incompressible, the substantial derivative in (2) is equal to zero for the fluid component. Thus, the mass balance for the oil leads to the incompressibility constraint

$$
\nabla \cdot v_{f}=0 .
$$

The deformations of the proppant are supposed to be small, and the mass balance for the proppant component reduces to the following equation for the proppant density:

$$
\rho_{p}(\boldsymbol{r}, t)=\rho_{p}(\boldsymbol{r}, 0)\left[1+\operatorname{tr}\left(\boldsymbol{\varepsilon}_{p}(\boldsymbol{r}, t)\right)\right],
$$

where $\operatorname{tr}\left(\boldsymbol{\varepsilon}_{p}\right)$ is the first invariant of strain tensor $\boldsymbol{\varepsilon}_{p}$.

The balance of momentum for both components in the local form reads

$$
\rho_{i} \frac{\delta_{i} \boldsymbol{v}_{i}}{\delta t}=\rho_{i} \boldsymbol{f}_{e}+\boldsymbol{f}_{\mathrm{in}}+\nabla \cdot \boldsymbol{T}_{i},
$$

where $f_{e}$ is the external body force density, $f_{\text {in }}$ is the internal volumetric force density, and $\boldsymbol{T}_{i}$ is the Cauchy stress tensor.

Gravity is the only external body force. The internal volumetric force represents the interaction between two continua, namely oil and proppant. This force should depend on the densities of both components and be eliminated in the balance equation for the whole media. The internal volumetric force can be written as

$$
\boldsymbol{f}_{\mathrm{in}}=\frac{\rho_{f} \rho_{p}}{\rho_{f}+\rho_{p}} \boldsymbol{f}_{f p}^{d}
$$

where $\boldsymbol{f}_{f p}^{d}$ is the interaction force between oil and proppant per unit mass. 
The interaction between fluid and proppant is due to the presence of viscous frictional forces caused between two continua when the oil flows through a proppant pack. The occurring friction depends on the relative velocity of the components. The main parameter determining the magnitude of the corresponding force is the coefficient of viscous friction between the two components, which depends on many factors, including the type of proppant coating, its size and shape, the rheological properties of oil, etc.

Here, we assume a linear dependence of the dissipative components of the forces on the difference in the velocities of the two components. Since we solve a quasistatic problem for the proppant and do not consider the proppant motion, the following equation holds:

$$
\boldsymbol{f}_{f p}^{d}=\mu_{f p} \boldsymbol{v}_{f},
$$

where $\mu_{f p}$ is the coefficient of viscous friction between proppant and oil.

Thus, the balance of momentum for fluid in the local form can be rewritten as

$$
\rho_{f}\left(\frac{\partial \boldsymbol{v}_{f}}{\partial t}+\boldsymbol{v}_{f} \cdot \nabla \boldsymbol{v}_{f}\right)=\rho_{f} \boldsymbol{g}+\frac{\rho_{f} \rho_{p}}{\rho_{f}+\rho_{p}} \boldsymbol{f}_{f p}^{d}+\nabla \cdot \boldsymbol{T}_{f},
$$

where $\boldsymbol{g}$ is the gravitational acceleration.

Note that in the stationary case the partial derivative in (9) is absent, because the flow is steady and the velocity in each point of observation does not change with time.

The appropriate constitutive relation for a linear incompressible fluid reads

$$
\boldsymbol{T}_{f}=-\rho_{f} \boldsymbol{E}+\frac{\rho_{f}}{\rho_{f}+\rho_{p}} 2 \mu_{f}(\nabla \boldsymbol{v})^{s},
$$

where $p_{f}$ is the hydrostatic oil pressure, $\boldsymbol{E}$ is the unit tensor, $\mu_{f}$ is the coefficient of dynamic viscosity of the oil, and $(\nabla \boldsymbol{v})^{s}$ is the symmetric part of the velocity gradient.

Since a quasistatic proppant behavior is considered, the balance of momentum for proppant reduces to

$$
\rho_{p} \boldsymbol{g}-\frac{\rho_{f} \rho_{p}}{\rho_{f}+\rho_{p}} \boldsymbol{f}_{f p}^{d}+\nabla \cdot \boldsymbol{T}_{p}=0 .
$$

We suppose the proppant to be a linear isotropic elastic material satisfying Hooke's law:

$$
\boldsymbol{T}_{p}=\frac{\rho_{p}}{\rho_{f}+\rho_{p}}\left(\frac{E v}{(1+v)(1-2 v)} \operatorname{tr}\left(\boldsymbol{\varepsilon}_{p}\right) \boldsymbol{E}+\frac{E}{1+v} \boldsymbol{\varepsilon}_{p}\right),
$$

where $E$ and $v$ are Young's modulus and Poisson's ratio, respectively, $\boldsymbol{\varepsilon}_{p}$ is the linear strain tensor of the proppant, and $\boldsymbol{\varepsilon}_{p}=\left(\nabla \boldsymbol{u}_{p}\right)^{s}$, where $\boldsymbol{u}_{p}$ is the proppant displacement. 
Finally, let us assume that all variables do not depend on the $y$ coordinate so that we can consider a state of plane-strain. Then by taking all of the simplifications into account, the whole system of equations in coordinate form is given by (13)-(19):

- equation for the proppant density

$$
\rho_{p}(\boldsymbol{r}, t)=\rho_{p}(\boldsymbol{r}, 0)\left(1+\frac{\partial u_{x}}{\partial x}+\frac{\partial u_{z}}{\partial z}\right),
$$

- incompressibility condition for the oil

$$
\frac{\partial v_{f x}}{\partial x}+\frac{\partial v_{f z}}{\partial z}=0
$$

- the balance of momentum for the oil along the $x$ axis

$$
\begin{aligned}
\rho_{f}\left[\frac{\partial v_{f x}}{\partial t}+v_{f x} \frac{\partial v_{f x}}{\partial t}+v_{f z} \frac{\partial v_{f x}}{\partial z}\right] & \\
=-\rho_{f} g-\frac{\partial p_{f}}{\partial x}+ & \frac{\rho_{f} \rho_{p}}{\rho_{f}+\rho_{p}} \mu_{f p} v_{f x}+\frac{\rho_{f}}{\rho_{f}+\rho_{p}} \mu_{f}\left[\frac{\partial^{2} v_{f x}}{\partial x^{2}}+\frac{1}{2}\left(\frac{\partial^{2} v_{f x}}{\partial z^{2}}+\frac{\partial^{2} v_{f z}}{\partial z \partial x}\right)\right] \\
& \quad-\frac{\rho_{f}}{\left(\rho_{f}+\rho_{p}\right)^{2}} \mu_{f}\left[\frac{\partial v_{f x}}{\partial x} \frac{\partial \rho_{p}}{\partial x}+\frac{1}{2}\left(\frac{\partial v_{f z}}{\partial x}+\frac{\partial v_{f x}}{\partial z}\right) \frac{\partial \rho_{p}}{\partial z}\right],
\end{aligned}
$$

- the balance of momentum for the oil along the $z$ axis

$$
\begin{aligned}
& \rho_{f}\left[\frac{\partial v_{f z}}{\partial t}+v_{f x} \frac{\partial v_{f z}}{\partial x}+v_{f z} \frac{\partial v_{f z}}{\partial z}\right] \\
&=-\frac{\partial p_{f}}{\partial z}+\frac{\rho_{f} \rho_{p}}{\rho_{f}+\rho_{p}} \mu_{f p} v_{f z}+\frac{\rho_{f}}{\rho_{f}+\rho_{p}} \mu_{f}\left[\frac{\partial^{2} v_{f z}}{\partial z^{2}}+\frac{1}{2}\left(\frac{\partial^{2} v_{f z}}{\partial x^{2}}+\frac{\partial^{2} v_{f x}}{\partial x \partial z}\right)\right] \\
& \quad-\frac{\rho_{f}}{\left(\rho_{f}+\rho_{p}\right)^{2}} \mu_{f}\left[\frac{\partial v_{f z}}{\partial z} \frac{\partial \rho_{p}}{\rho_{z}}+\frac{1}{2}\left(\frac{\partial v_{f z}}{\partial z}+\frac{\partial v_{f x}}{\partial z}\right) \frac{\partial \rho_{p}}{\partial x}\right]
\end{aligned}
$$

- the balance of momentum for the proppant along the $x$ axis

$$
\begin{aligned}
& \rho_{p} g-\frac{\rho_{f} \rho_{p}}{\rho_{f}+\rho_{p}} \mu_{f p} v_{f x} \\
& +\frac{\rho_{p}}{\rho_{p}+\rho_{f}} \frac{E}{1+v}\left[\frac{1}{2}\left(\frac{\partial^{2} u_{p z}}{\partial z \partial x}+\frac{\partial^{2} u_{p x}}{\partial z^{2}}\right)+\frac{1-v}{1-2 v} \frac{\partial^{2} u_{p x}}{\partial x^{2}}+\frac{v}{1-2 v} \frac{\partial^{2} u_{p z}}{\partial x \partial z}\right] \\
& -\frac{\rho_{f}}{\left(\rho_{f}+\rho_{p}\right)^{2}} \frac{E}{1+v}\left[\frac{\partial \rho_{p}}{\partial x}\left(\frac{1-v}{1-2 v} \frac{\partial u_{p x}}{\partial x}+\frac{v}{1-2 v} \frac{\partial u_{p z}}{\partial z}\right)+\frac{1}{2}\left(\frac{\partial u_{p z}}{\partial x}+\frac{\partial u_{p x}}{\partial z}\right) \frac{\partial \rho_{p}}{\partial z}\right]=0,
\end{aligned}
$$


- the balance of momentum for the proppant along the $z$ axis

$-\frac{\rho_{f} \rho_{p}}{\rho_{f}+\rho_{p}} \mu_{f p} v_{f z}$

$+\frac{\rho_{p}}{\rho_{p}+\rho_{f}} \frac{E}{1+v}\left[\frac{1}{2}\left(\frac{\partial^{2} u_{p z}}{\partial x^{2}}+\frac{\partial^{2} u_{p x}}{\partial x \partial z}\right)+\frac{1-v}{1-2 v} \frac{\partial^{2} u_{p z}}{\partial z^{2}}+\frac{v}{1-2 v} \frac{\partial^{2} u_{p x}}{\partial x \partial z}\right]$

$-\frac{\rho_{f}}{\left(\rho_{f}+\rho_{p}\right)^{2}} \frac{E}{1+v}\left[\frac{\partial \rho_{p}}{\partial z}\left(\frac{1-v}{1-2 v} \frac{\partial u_{p z}}{\partial x}+\frac{v}{1-2 v} \frac{\partial u_{p x}}{\partial x}\right)+\frac{1}{2}\left(\frac{\partial u_{p z}}{\partial x}+\frac{\partial u_{p x}}{\partial z}\right) \frac{\partial \rho_{p}}{\partial x}\right]=0$,

- and flowback criterion in the coordinate form

$$
\mu_{p}\left((1-v) \frac{\partial u_{p z}}{\partial z}+v \frac{\partial u_{p x}}{\partial x}\right)<\left((1-v) \frac{\partial u_{p x}}{\partial x}+v \frac{\partial u_{p z}}{\partial z}\right) k\left[1-\exp \left(\frac{d-z_{0}}{z_{0}}\right)\right] \text {. }
$$

3.2. Boundary and initial conditions. The initial distribution of the proppant grains along the fracture and the final shape of the fracture are supposed to be known, e.g., from a solution of the corresponding boundary-value problem.

As has been mentioned already, the presence of the wellbore and the rock surrounding the fracture will be accounted for by the boundary conditions, namely the pressures at the fracture edges and at the bottom of the crack and its tip.

When modeling hydraulic fracture usually it is assumed that the value of the pressure acting at the crack edges at the initial time is equal or close to the value of the rock pressure. The function of the pressure decrease depends on the amount of fluid flow. Note that this pressure depends only on the oil flow and does not depend on the proppant behavior. It means that one can suppose that the rock is acting only on oil:

$$
\left.T_{f z z}\right|_{z_{1}(x)}=P_{r},\left.\quad T_{f z z}\right|_{z_{2}(x)}=-P_{r},
$$

where $T_{f z z}$ is the component of the stress tensor of oil acting in the direction of the crack opening, $z_{1}(x)$ and $z_{2}(x)$ are functions with respect to the crack edges (see Figure 1), and $P_{r}$ is the rock pressure.

Apart from the rock pressure, there is closure stress acting at the crack edges. So in fact both rock pressure and closure stress act on the two-component continuum. Equation (20) leads to the assumption that the closure stress affects only the proppant (since the rock pressure acts on only the oil) and does not affect the oil. Such an assumption is correct from the mechanical point of view since the proppant does not allow for closing the fracture. Hence, the proppant particles are most affected by the stress that tends to close the crack edges. Consequently, the following boundary conditions hold:

$$
\left.T_{p z z}\right|_{z_{1}(x)}=\sigma_{r},\left.\quad T_{p z z}\right|_{z_{2}(x)}=-\sigma_{r},
$$


where $\sigma_{r}$ is the closure stress. Many authors note that this stress affects proppant flowback and consider it as one of the main terms to control the proppant flowback [Milton-Tayler et al. 1992; Asgian et al. 1995; McLennan et al. 2015; Andrews and Kjørholt 1998; Canon et al. 2003; Aidagulov et al. 2007; Vo et al. 2014; Lu et al. 2016; Barree and Conway 2001; Larsen and Smith 1985; Ely et al. 1990]. The value of the closure stress is significant enough to hold the packed proppant in the fracture even when the outgoing force is big enough.

Apart from stresses acting at the crack edges, it is necessary to take into account the oil flow along the crack's boundary. If the fracture geometry is simple, it is permissible to assume that the inflow is perpendicular to the fracture boundary. Hence, the following conditions hold:

$$
\begin{array}{rlrl}
\left.\boldsymbol{t} \cdot \boldsymbol{v}_{f}\right|_{z_{1}(x)} & =0, & \left.\rho_{f} \boldsymbol{n} \cdot \boldsymbol{v}_{f}\right|_{z_{1}(x)}=\left.D\left(\rho_{f}-\rho_{f}^{p}\right)\right|_{z_{1}(x)}, \\
\left.\boldsymbol{t} \cdot \boldsymbol{v}_{f}\right|_{z_{2}(x)}=0, & \left.\rho_{f} \boldsymbol{n} \cdot \boldsymbol{v}_{f}\right|_{z_{2}(x)}=\left.D\left(\rho_{f}-\rho_{f}^{p}\right)\right|_{z_{2}(x)},
\end{array}
$$

where $\boldsymbol{t}$ is the vector tangent to the fracture boundary, $\boldsymbol{n}$ is the outer normal vector, $D$ is the oil permeability coefficient, and $\rho_{f}^{p}$ is the oil concentration in the rock.

We assume that the proppant particles at the crack edges adhere to them. It means that these particles cannot be removed from the crack. From a mechanical point of view, this assumption can be justified by the fact that the velocity of the laminar flow of oil and, accordingly, the probability of proppant transport are higher when approaching from the periphery to the center of the channel formed by the cleavage. Then the components of displacement at the boundary read

$$
\left.u_{p x}\right|_{z_{1}(x) \cdot z_{2}(x)}=\left.u_{p z}\right|_{z_{1}(x) \cdot z_{2}(x)}=0 .
$$

Finally, it is necessary to define the boundary conditions at the bottom of the crack and at its tip. We assume that there is a pressure difference inside of the crack initiated by a bottom stress and the rock pressure.

In the case of a stationary problem, there will be a constant pressure difference, whereas in the case of a transient flow it is necessary to allow for the possibility of changes in the external conditions. Practically, such changes are usually very fast and can be observed in the case when the bottom pressure, determined by the operating conditions, significantly changes in time. Then the boundary conditions should depend on time and vary according to a certain prescribed law.

The following conditions hold:

$$
\left.T_{f x x}\right|_{x=0}=P_{b},\left.\quad T_{f x x}\right|_{x=l_{f}}=-P_{r},
$$

where $T_{f x x}$ is the component of the stress tensor of oil acting in the directions of the fracture length, $l_{f}$ is the fracture length, and $P_{b}$ is the bottom pressure.

Finally, in order to solve the nonstationary problem, it is necessary to set the 
initial conditions for the oil flow velocity and for the proppant displacement. We assume that at the initial moment the following conditions hold:

$$
\left.v_{f x}\right|_{t=0}=\left.v_{f z}\right|_{t=0}=0,\left.\quad u_{p x}\right|_{t=0}=\left.u_{p z}\right|_{t=0}=0 .
$$

\section{Conclusion}

In this paper, a local stability criterion is proposed in order to verify the possible occurrence of proppant flowback as a function of the physical and mechanical properties of the proppant and of the oil, the external pressures, the geometric dimensions of the fracture, and the ratio of the average proppant particle size to the crack opening width. In order to obtain the stress components involved in the developed criterion, a physicomathematical model for the determination of the proppant strain-stress state was presented. The proposed model is based on a continuum description of a two-component medium consisting of oil, modeled by the Newtonian incompressible fluid, and the proppant, modeled by a linear-elastic deformable solid. We considered steady-state oil flow for estimating the probability of proppant flowback occurrence under regular conditions and transient flow for taking the possibility of fast changing of the external conditions into account.

\section{Acknowledgments}

This work was supported by the Ministry of Science and Higher Education of the Russian Federation within the framework of the Federal Program "Research and development in priority areas for the development of the scientific and technological complex of Russia for 2014-2020" (activity 1.2), grant No. 14.575.21.0146 of 26 September 2017, unique identifier: RFMEFI57517X0146. The industrial partner of the grant is LLC Gazprom-neft Science \& Technology Centre.

\section{References}

[Aidagulov et al. 2007] G. R. Aidagulov, M. J. Thiercelin, V. N. Nikolaevskiy, S. Kapustyanskiy, and A. Zhilenkov, "Prediction of long-term proppant flowback in weak rocks", in SPE Hydraulic Fracturing Technology Conference (College Station, TX, 2007), Society of Petroleum Engineers, Richardson, TX, 2007.

[Andrews and Kjørholt 1998] J. S. Andrews and H. Kjørholt, "Rock mechanical principles help to predict proppant flowback from hydraulic fractures", pp. 381-390 in SPE/ISRM Rock Mechanics in Petroleum Engineering (Trondheim, Norway, 1998), Society of Petroleum Engineers, Richardson, TX, 1998.

[Asgian et al. 1995] M. I. Asgian, P. A. Cundall, and B. H. G. Brady, "The mechanical stability of propped hydraulic fractures: a numerical study”, J. Petrol. Technol. 47:3 (1995), 203-208.

[Barree and Conway 2001] R. D. Barree and M. W. Conway, "Proppant holdup, bridging, and screenout behavior in naturally fractured reservoirs", in SPE Production and Operations Symposium (Oklahoma City, 2001), Society of Petroleum Engineers, Richardson, TX, 2001. 
[Brazgina et al. 2016] O. V. Brazgina, E. A. Ivanova, and E. N. Vilchevskaya, "Saturated porous continua in the frame of hybrid description", Contin. Mech. Therm. 28:5 (2016), 1553-1581.

[Canon et al. 2003] J. M. Canon, D. J. Romero, T. T. Pham, and P. P. Valko, "Avoiding proppant flowback in tight-gas completions with improved fracture design", in SPE Annual Technical Conference and Exhibition (Denver, 2003), Society of Petroleum Engineers, Richardson, TX, 2003.

[Ely et al. 1990] J. W. Ely, W. T. Arnold III, and S. A. Holditch, "New techniques and quality control find success in enhancing productivity and minimizing proppant flowback", pp. 889-898 in SPE Annual Technical Conference and Exhibition (New Orleans, 1990), Society of Petroleum Engineers, Richardson, TX, 1990.

[Ivanova et al. 2016] E. A. Ivanova, E. N. Vilchevskaya, and W. H. Müller, "Time derivatives in material and spatial description - what are the differences and why do they concern us?", pp. 3-28 in Advanced methods of continuum mechanics for materials and structures, edited by K. Naumenko and M. Aßmus, Advanced Structured Materials 60, Springer, 2016.

[Larsen and Smith 1985] D. G. Larsen and L. J. Smith, "New conductivity found in angular blends of fracturing sand", pp. 205-210 in SPE Production Operations Symposium (Oklahoma City, 1985), Society of Petroleum Engineers, Richardson, TX, 1985.

[Lu et al. 2016] W. Lu, B. O’Neil, K. Zhang, C. Wang, and H. Quintero, "Enhancing proppant flowback control through surface treatment of proppant", in International Petroleum Technology Conference (Bangkok, 2016), International Petroleum Technology Conference, Richardson, TX, 2016.

[Manderscheid and Gyekenyesi 1987] J. M. Manderscheid and J. P. Gyekenyesi, "Fracture mechanics concepts in reliability analysis of monolithic ceramics", NASA Technical Memorandum 100174, NASA Lewis Research Center, 1987, https://ntrs.nasa.gov/search.jsp?R=19870017836.

[McLennan et al. 2015] J. McLennan, I. Walton, J. Moore, D. Brinton, and J. Lund, "Proppant backflow: mechanical and flow considerations", Geothermics 57 (2015), 224-237.

[Milton-Tayler et al. 1992] D. Milton-Tayler, C. Stephenson, and M. I. Asgian, "Factors affecting the stability of proppant in propped fractures: results of a laboratory study", pp. 569-580 in SPE Annual Technical Conference and Exhibition (Washington, DC, 1992), Society of Petroleum Engineers, Richardson, TX, 1992.

[Vo et al. 2014] L. K. Vo, P. D. Nguyen, F. Liang, and C. Parton, "Enhancing proppant pack conductivity with consolidation and agglomeration performance: a laboratory study", in SPE International Symposium and Exhibition on Formation Damage Control (Lafayette, LA, 2014), Society of Petroleum Engineers, Richardson, TX, 2014.

Received 5 Sep 2018. Revised 4 Oct 2018. Accepted 11 Nov 2018.

KsEnia P. Frolova: kspfrolova@gmail.com

POLINA M. GRIGOREVA: polina.grigoreva239@gmail.com

Peter the Great Saint Petersburg Polytechnic University, Saint Petersburg, Russia

and

Institute for Problems in Mechanical Engineering, Russian Academy of Sciences, Saint Petersburg, Russia

KOnSTANTIN E. LEZHNEV: lezhnev.ke@gazpromneft-ntc.ru

GRIGORIY V. PADERIN: paderin.gv@gazpromneft-ntc.ru

Gazprom-neft Science \& Technology Centre, Saint Petersburg, Russia 
EDITORIAL BOARD

ANTONIO CARCATERRA

ERIC A. CARLEN

FRANCESCO DELL'ISOLA

RAFFAELE ESPOSITO

ALBERT FANNJIANG

Gilles A. FrancFort

Pierangelo Marcati

JEAN-JACQUES MARIGO

PETER A. MARKOWICH

MARTIN OSTOJA-STARZEWSKI

PIERRE SEPPECHER

DAVID J. STEIGMANN

PAUL STEINMANN

PierRe M. SuQueT

MANAGING EDITORS

MICOL AMAR

ANGELA MADEO

MARTIN OSTOJA-STARZEWSKI

\section{ADVISORY BOARD}

ADNAN AKAY

Holm AltenbaCH

MICOL AMAR

HARM ASKES

TEODOR ATANACKOVIĆ

VICTOR BERDICHEVSKY

GuY BouchitTÉ

ANDREA BRAIDES

ROBERTO CAMASSA

MAURO CARFORE

ERIC DARVE

FELIX DARVE

ANNA DE MASI

Gianpietro Del Piero

Emmanuele Di Benedetto

VICTOR A. EREMEYEV

BERNOLD FIEDLER

IRENE M. GAMBA

DAVID Y. GAO

SERGEy GaVRILYUK

Timothy J. HeAley

DOMINIQUE JEULIN

ROgER E. KHAYAT

CORRADO LATTANZIO

ROBERT P. LIPTON

ANGELO LUONGO

ANGEla MADEO

JUAN J. MANFREDI

CARlo MARCHIORO

ANIL MISRA

ROBERTO NATALINI

PATRIZIO NEFF

Thomas J. Pence

ANDREY PIATNITSKI

ERRICO PRESUTtI

MARIO PUlVIRENTI

Lucio Russo

Miguel A. F. SANJUAN

PATRICK SElvaduraI

MIROSLAV ŠILHAVÝ

GUIDO SWEERS

ANTOINETTE TORDESILLAS

LEV TRUSKINOVSKY

JUAN J. L. VELÁZQUEZ

VINCENZO VESPRI

ANGELO VULPIANI msp.org/memocs

Università di Roma "La Sapienza", Italia

Rutgers University, USA

(CO-CHAIR) Università di Roma "La Sapienza", Italia

(TREASURER) Università dell'Aquila, Italia

University of California at Davis, USA

(CO-CHAIR) Université Paris-Nord, France

Università dell' Aquila, Italy

École Polytechnique, France

DAMTP Cambridge, UK, and University of Vienna, Austria

(CHAIR MANAGING EDITOR) Univ. of Illinois at Urbana-Champaign, USA

Université du Sud Toulon-Var, France

University of California at Berkeley, USA

Universität Erlangen-Nürnberg, Germany

LMA CNRS Marseille, France

Università di Roma "La Sapienza", Italia

Université de Lyon-INSA (Institut National des Sciences Appliquées), France (CHAIR MANAGING EDITOR) Univ. of Illinois at Urbana-Champaign, USA

Carnegie Mellon University, USA, and Bilkent University, Turkey

Otto-von-Guericke-Universität Magdeburg, Germany

Università di Roma "La Sapienza”, Italia

University of Sheffield, UK

University of Novi Sad, Serbia

Wayne State University, USA

Université du Sud Toulon-Var, France

Università di Roma Tor Vergata, Italia

University of North Carolina at Chapel Hill, USA

Università di Pavia, Italia

Stanford University, USA

Institut Polytechnique de Grenoble, France

Università dell' Aquila, Italia

Università di Ferrara and International Research Center MEMOCS, Italia

Vanderbilt University, USA

Gdansk University of Technology, Poland

Freie Universität Berlin, Germany

University of Texas at Austin, USA

Federation University and Australian National University, Australia

Université Aix-Marseille, France

Cornell University, USA

École des Mines, France

University of Western Ontario, Canada

Università dell' Aquila, Italy

Louisiana State University, USA

Università dell'Aquila, Italia

Université de Lyon-INSA (Institut National des Sciences Appliquées), France University of Pittsburgh, USA

Università di Roma "La Sapienza", Italia

University of Kansas, USA

Istituto per le Applicazioni del Calcolo "M. Picone", Italy

Universität Duisburg-Essen, Germany

Michigan State University, USA

Narvik University College, Norway, Russia

Università di Roma Tor Vergata, Italy

Università di Roma “La Sapienza”, Italia

Università di Roma “Tor Vergata", Italia

Universidad Rey Juan Carlos, Madrid, Spain

McGill University, Canada

Academy of Sciences of the Czech Republic

Universität zu Köln, Germany

University of Melbourne, Australia

École Polytechnique, France

Bonn University, Germany

Università di Firenze, Italia

Università di Roma La Sapienza, Italia

MEMOCS (ISSN 2325-3444 electronic, 2326-7186 printed) is a journal of the International Research Center for the Mathematics and Mechanics of Complex Systems at the Università dell'Aquila, Italy.

Cover image: "Tangle” by $\odot$ John Horigan; produced using the Context Free program (contextfreeart.org).

PUBLISHED BY

7 mathematical sciences publishers

nonprofit scientific publishing

http://msp.org/

(C) 2019 Mathematical Sciences Publishers 
Mathematics and Mechanics of Complex Systems vol. 7 no. 2

A polynomial chaos expanded hybrid fuzzy-stochastic model for transversely fiber reinforced plastics

Eduard Penner, Ismail Caylak, Alex Dridger and Rolf Mahnken

Dynamic boundary conditions for membranes whose surface energy depends on the mean and Gaussian curvatures

Sergey Gavrilyuk and Henri Gouin Energy-based trajectory tracking and vibration control for multilink highly flexible manipulators

Ivan Giorgio and Dionisio Del Vescovo

A model of the proppant flowback: setup of the theoretical framework

Ksenia P. Frolova, Polina M. Grigoreva, Konstantin E.

Lezhnev and Grigoriy V. Paderin

The object detection by autonomous apparatus as a solution of the 189 Buffon needle problem

Mikhail A. Guzev, Gurami S. Tsitsiashvili and Marina A.

Osipova

MEMOCS is a journal of the International Research Center for the Mathematics and Mechanics of Complex Systems at the Università dell' Aquila, Italy.

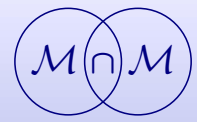

